\title{
Prognostic significance of high-sensitivity cardiac troponin in patients with heart failure with preserved ejection fraction
}

\author{
Sho Suzuki ${ }^{1} \cdot$ Hirohiko Motoki $^{1}$ (1) - Masatoshi Minamisawa ${ }^{1} \cdot$ Yukari Okuma $^{1} \cdot$ Wataru Shoin $^{1} \cdot$ Takahiro Okano $^{1}$. \\ Kazuhiro Kimura $^{1} \cdot$ Soichiro Ebisawa ${ }^{1} \cdot$ Ayako Okada $^{1} \cdot$ Koichiro Kuwahara $^{1}$
}

Received: 8 February 2019 / Accepted: 22 March 2019 / Published online: 30 March 2019

(c) The Author(s) 2019

\begin{abstract}
The aim of this study was to investigate the prognostic significance of high-sensitivity troponin $\mathrm{T}$ (hs-TnT) in patients with heart failure (HF) with preserved ejection fraction (HFpEF). We enrolled consecutive patients admitted to Shinshu University Hospital for HF treatment between July 2014 and March 2017 and stratified them into HF with reduced ejection fraction and HFpEF groups (left ventricular ejection fraction, $<50 \%$ and $\geq 50 \%$, respectively). Hs-TnT was evaluated at discharge, and patients were prospectively monitored for all-cause mortality, non-fatal myocardial infarction, stroke, and HF hospitalization. In 155 enrolled patients (median age 76 years), during a median follow-up of 449 days, 60 experienced an adverse event. Hs-TnT was significantly higher in patients with adverse events than in those without in HFpEF $(p=0.003)$. Hs-TnT did not significantly correlate with age, sex, hemoglobin, albumin, eGFR, or BNP. In Kaplan-Meier analysis, high hs-TnT predicted a poor prognosis in HFpEF $(p=0.003)$. In multivariate Cox regression analysis, hs-TnT levels independently predicted adverse events in HFpEF ( $p=0.003$ ) after adjusting for age and eGFR [HR, 1.015 (95\% CI, 1.005-1.025), $p=0.004$ ], and age and BNP [HR 1.016 (95\% CI 1.005-1.027), $p=0.005$ ]. Elevated hs-TnT at discharge predicted adverse events in HFpEF.
\end{abstract}

Keywords Heart failure with preserved ejection fraction $\cdot$ High-sensitivity troponin $\mathrm{T} \cdot$ Prognosis

\section{Introduction}

Approximately half of all patients hospitalized with heart failure (HF) have a normal left ventricular ejection fraction (LVEF), a condition known as HF with preserved ejection fraction (HFpEF) [1]. The mortality rate of patients with $\mathrm{HFpEF}$ is reportedly comparable to that of those with HF with reduced ejection fraction (HFrEF) [2]. Thus, tools for risk-stratification in hospitalized patients with $\mathrm{HFpEF}$ are needed to improve the management of these patients.

B-type natriuretic peptide (BNP) and N-terminal proBNP have been used for HF diagnosis, prognosis, and management, as established biomarkers. Additionally, there has been increased interest in the utility of troponin, a biomarker of myocardial necrosis, to predict prognosis in patients with HF [3]. Current HF guidelines recommend troponin

Hirohiko Motoki

hmotoki@shinshu-u.ac.jp

1 Department of Cardiovascular Medicine, Shinshu University School of Medicine, Asahi 3-1-1, Matsumoto 3908621, Nagano, Japan measurement on hospital admission to establish prognosis in cases of acutely decompensated HF [4, 5]. However, these recommendations are based on studies that included not only patients with HFpEF, but also those with HFrEF. Several studies have demonstrated a consistent association between elevated troponin and adverse clinical outcomes in patients with HFrEF [6, 7]. On the other hand, the prognostic value of troponin in HFpEF patients is not well-established.

The introduction of high-sensitivity assays has allowed the accurate detection of very low levels of circulating cardiac troponins in stable HF [8]. Compared to the cardiac troponin $\mathrm{T}$ (cTnT), the high-sensitivity troponin $\mathrm{T}$ (hs-TnT) assay is expected to demonstrate superior clinical performance in the setting of cardiovascular events. While a few previous investigators evaluated the prognostic value of troponin in HFpEF retrospectively, these studies assessed the efficacy of cardiac troponin I (cTnI) or a combination of cTnI and cTnT $[9,10]$. Therefore, we aimed to investigate the prognostic significance of hs-TnT in patients hospitalized for decompensated HFpEF. 


\section{Materials and methods}

\section{Study population}

This study enrolled consecutive patients admitted to Shinshu University Hospital for HF treatment between July 2014 and March 2017 with the exception of acute coronary syndrome. Informed consent was obtained after the HF treatment. Then, patients were enrolled at the compensated state of HF before discharge. We recorded baseline clinical characteristics including age, sex, medical history, HF etiology, major risk factors for coronary heart disease (hypertension, smoking, diabetes, and dyslipidemia), comorbidities, and HF medications in all registered patients. We performed blood tests and echocardiography at discharge.

The diagnosis of HF was made by symptoms, physical examinations, chest X-rays, echocardiography, and blood tests. The diagnosis of acute coronary syndrome was made by treating clinicians using symptoms, electrocardiograms, echocardiography, blood tests, chest X-rays, and available coronary angiograms. Patients underwent a registration examination when they became clinically stable following HF treatment.

We performed transthoracic echocardiography using standardized equipment (Vivid E9 Ultrasound Machine; GE Healthcare, Chicago, IL, US) in compliance with the recommendations of the American Society of Echocardiography [11]. The biplane modified Simpson's method was used to measure LVEF. We stratified patients into HFrEF (LVEF < 50\%) and HFpEF (LVEF $\geq 50 \%$ ) subgroups according to their LVEF at discharge. We measured hs-TnT at discharge using an electrochemiluminescence immunoassay and a Cobas e411 analyzer (Roche Diagnostics $\mathrm{GmBH}$, Mannheim, Germany). The measurement range of the hsTnT assay was 3-10,000 ng/L with a coefficient of variation of $15 \%$ at the level of $3 \mathrm{ng} / \mathrm{L}$.

The Shinshu University School Hospital Ethics Committee approved the study protocol. The investigation confirms the principles outlined in the Declaration of Helsinki.

\section{Follow-up}

Patients were prospectively monitored for major adverse cardiac events (all-cause mortality, non-fatal myocardial infarction, non-fatal stroke, and HF hospitalizations) through scheduled telephone follow-up, and incidents were validated by chart review.

\section{Statistical analysis}

Continuous variables are summarized as means \pm standard deviation if normally distributed and as medians with interquartile range if non-normally distributed. Normality was assessed by the Shapiro-Wilk $W$ test. Comparisons of baseline characteristics were made with a contingency table for categorical variables, $t$ test for normally distributed continuous variables, and either the Wilcoxon or Mann-Whitney test for non-normally distributed continuous variables. Spearman's rank correlation method was used as a nonparametric measure of association between hs-TnT and clinical and laboratory indices. The optimal receiver operating characteristic (ROC) curve cutoff value for prediction of adverse clinical events was chosen as the value maximizing sensitivity and specificity. Kaplan-Meier survival plots were calculated from baseline to time of adverse event and compared using the log-rank test. Cox proportional hazards analysis was used to evaluate the independent prognostic utility of hsTnT. The covariates used were age, sex, estimated glomerular filtration rate (eGFR), hemoglobin, albumin, and BNP. A $p$ value $<0.05$ was considered statistically significant. The statistical analyses were performed using SPSS Statistics for Windows, Version 24 (IBM Corp., Armonk, NY, US).

\section{Results}

\section{Study population}

We enrolled 155 patients (mean age, 76; male, 62\%). Sixtyfour $(41 \%)$ patients had HFpEF, and 91 (59\%) had HFrEF. Table 1 shows baseline patient characteristics stratified by HF group. In terms of comorbidities, 88 (57\%) patients had atrial fibrillation, which was relatively high. Among them, 4 patients ( 3 patients in HFpEF, 1 patient in HFrEF) had a history of previous catheter ablation. Other patients were treated by anticoagulant therapy, and either medical rate control or rhythm control. In total, 11 patients ( 2 patients in $\mathrm{HFpEF}, 9$ patients in $\mathrm{HFrEF}$ ) underwent percutaneous coronary intervention during hospitalization due to newly diagnosed coronary artery disease. Compared to those who did not develop adverse events, patients who did were older and had higher hs-TnT in the HFpEF (36 [20-66] ng/L vs. 21 [15-32] ng/L, p=0.003) and HFrEF (40 [29-71] ng/L vs. 27 $[16-50] \mathrm{ng} / \mathrm{L}, \mathrm{p}=0.005)$ groups. There were no significant differences in BNP levels in patients with and without an adverse event. In the HFpEF group, albumin, hemoglobin, and eGFR were lower in patients who developed adverse events than in those who were event-free. However, there were no significant correlations between hs-TnT and these clinical indices (Table 2). 
Table 1 Baseline characteristics in patients with heart failure

\begin{tabular}{|c|c|c|c|c|c|c|c|}
\hline \multirow[t]{3}{*}{ Variable } & \multirow{3}{*}{$\begin{array}{l}\text { Overall population } \\
(n=155)\end{array}$} & \multicolumn{3}{|l|}{$\operatorname{HFpEF}(n=64)$} & \multicolumn{3}{|l|}{$\operatorname{HFrEF}(n=91)$} \\
\hline & & \multicolumn{3}{|c|}{ Adverse cardiac events } & \multicolumn{3}{|c|}{ Adverse cardiac events } \\
\hline & & Yes $(n=28)$ & No $(n=36)$ & $p$ value & Yes $(n=32)$ & No $(n=59)$ & $p$ value \\
\hline Age (years) [range] & $76[67-84]$ & $84 \pm 11$ & $75 \pm 11$ & 0.002 & 80 [70-84] & 69 [58-77] & $<0.001$ \\
\hline Male sex, $n(\%)$ & $96(62)$ & $16(57)$ & $16(44)$ & 0.313 & $22(69)$ & $42(71)$ & 0.808 \\
\hline BMI & $21.0[19.0-24.2]$ & $20.5[18.7-24.2]$ & $22.1[19.3-25.6]$ & 0.223 & 20.2 [17.9-22.7] & $21.0[19.2-24.1]$ & 0.16 \\
\hline $\begin{array}{l}\text { Systolic blood pressure, } \\
\mathrm{mmHg}\end{array}$ & $113 \pm 17$ & $119 \pm 17$ & $117 \pm 18$ & 0.568 & $107 \pm 15$ & $110 \pm 17$ & 0.423 \\
\hline $\begin{array}{l}\text { NYHA class III or IV, } \\
n(\%)\end{array}$ & $40(26)$ & $9(32)$ & $5(14)$ & 0.08 & $11(34)$ & $15(25)$ & 0.367 \\
\hline Ischemic etiology, $n(\%)$ & $50(32)$ & $7(25)$ & $8(22)$ & 0.795 & $16(50)$ & $19(32)$ & 0.096 \\
\hline Hypertension, $n(\%)$ & $82(53)$ & $17(61)$ & $22(61)$ & 0.974 & $11(34)$ & $32(54)$ & 0.07 \\
\hline Dyslipidemia, $n(\%)$ & $50(32)$ & $6(21)$ & $11(31)$ & 0.412 & $13(41)$ & $20(34)$ & 0.524 \\
\hline Diabetes mellitus, $n(\%)$ & $53(34)$ & $6(21)$ & $10(28)$ & 0.561 & $17(32)$ & $20(34)$ & 0.075 \\
\hline Atrial fibrillation, $n(\%)$ & $88(57)$ & $18(64)$ & $24(67)$ & 0.842 & $19(59)$ & $27(46)$ & 0.215 \\
\hline \multicolumn{8}{|l|}{ Medication } \\
\hline Antiplatelet, $n(\%)$ & $73(47)$ & $12(43)$ & $14(39)$ & 0.748 & $21(66)$ & $26(44)$ & 0.049 \\
\hline Anticoagulant, $n(\%)$ & $98(63)$ & $17(61)$ & $25(69)$ & 0.466 & $20(63)$ & $36(61)$ & 0.89 \\
\hline ACE-I, $n(\%)$ & $89(57)$ & $10(36)$ & $17(47)$ & 0.355 & $24(75)$ & $38(64)$ & 0.3 \\
\hline $\mathrm{ARB}, n(\%)$ & $38(25)$ & $8(28)$ & $12(22)$ & 0.683 & $5(16)$ & $13(22)$ & 0.464 \\
\hline ACE-I and/or ARB, $n(\%)$ & $126(81)$ & $18(64)$ & $28(78)$ & 0.234 & $29(91)$ & $51(86)$ & 0.559 \\
\hline Beta-blocker, $n(\%)$ & $111(72)$ & $12(43)$ & $22(61)$ & 0.147 & $26(81)$ & $51(86)$ & 0.512 \\
\hline MRA, $n(\%)$ & $92(59)$ & $17(61)$ & $21(58)$ & 0.847 & $17(53)$ & $37(63)$ & 0.374 \\
\hline Loop diuretic, $n(\%)$ & $127(82)$ & $24(86)$ & $29(81)$ & 0.587 & $29(91)$ & $45(76)$ & 0.093 \\
\hline Tolvaptan, $n(\%)$ & $37(24)$ & $6(21)$ & $6(17)$ & 0.628 & $10(31)$ & $15(25)$ & 0.552 \\
\hline \multicolumn{8}{|l|}{ Laboratory data } \\
\hline Alb (g/dL) & $3.5[3.3-3.9]$ & $3.4[3.2-3.5]$ & $3.6[3.3-3.8]$ & 0.006 & $3.6 \pm 0.5$ & $3.6 \pm 0.5$ & 0.97 \\
\hline $\mathrm{Hb}(\mathrm{g} / \mathrm{dL})$ & $11.7[10.4-13.6]$ & $10.7 \pm 1.4$ & $11.9 \pm 1.8$ & 0.004 & $11.7[10.3-12.9]$ & $12.9[10.8-14.4]$ & 0.063 \\
\hline $\operatorname{HbA1c}(\%)$ & $6.0[5.7-6.4]$ & $6.0[5.5-6.0]$ & $5.8[5.7-6.2]$ & 0.169 & $6.2[5.9-6.8]$ & $6.1[5.8-6.6]$ & 0.306 \\
\hline $\mathrm{eGFR}\left(\mathrm{mL} / \mathrm{min} / 1.73 \mathrm{~m}^{2}\right)$ & $45[31-58]$ & $35[28-48]$ & $51[36-69]$ & 0.005 & 38 [25-57] & $46[39-61]$ & 0.085 \\
\hline BNP, pg/mL & $269[140-479]$ & $240[160-376]$ & 134 [61-302] & 0.093 & 514 [241-649] & 291 [177-499] & 0.055 \\
\hline hs-TnT, ng/L & $30[19-50]$ & 36 [20-66] & $21[15-32]$ & 0.003 & $40[29-71]$ & $27[16-50]$ & 0.005 \\
\hline \multicolumn{8}{|l|}{ Echocardiographic data } \\
\hline $\operatorname{LVEF}(\%)$ & $46 \pm 16$ & $59[53-70]$ & $60[55-64]$ & 0.901 & $35[28-43]$ & $35[29-43]$ & 0.816 \\
\hline $\mathrm{LAD}(\mathrm{mm})$ & $49[43-55]$ & $51[45-62]$ & $50[45-54]$ & 0.253 & $50[45-56]$ & $47[42-52]$ & 0.043 \\
\hline LVEDV Index $\left(\mathrm{mL} / \mathrm{m}^{2}\right)$ & $68[47-87]$ & $48[38-57]$ & $42[38-56]$ & 0.967 & 80 [69-106] & 80 [66-95] & 0.461 \\
\hline LVESV Index $\left(\mathrm{mL} / \mathrm{m}^{2}\right)$ & $36[21-58]$ & $19[15-24]$ & $18[15-24]$ & 0.877 & $55[38-77]$ & 48 [36-66] & 0.348 \\
\hline $\operatorname{LVDd}(\mathrm{mm})$ & $54 \pm 9$ & $47 \pm 6$ & $48 \pm 6$ & 0.365 & $59 \pm 8$ & $57 \pm 9$ & 0.444 \\
\hline LVDs (mm) & $39[31-48]$ & $30 \pm 5$ & $31 \pm 6$ & 0.411 & $47 \pm 10$ & $47 \pm 10$ & 0.793 \\
\hline Severe AS & $4(3)$ & $0(0)$ & $1(4)$ & 0.437 & $2(6)$ & $1(2)$ & 0.282 \\
\hline Severe AR & $3(2)$ & $1(4)$ & $1(3)$ & 0.688 & $0(0)$ & $1(2)$ & 0.648 \\
\hline Severe MR & $13(8)$ & $1(4)$ & $6(17)$ & 0.096 & $4(13)$ & $2(3)$ & 0.111 \\
\hline Mitral E/A ratio & $1.0[0.7-1.8]$ & $1.33 \pm 0.36$ & $1.60 \pm 0.86$ & 0.264 & $0.92[0.67-1.65]$ & $0.92[0.65-1.83]$ & 0.885 \\
\hline Mitral DT (msec) & 163 [128-212] & 193 [142-225] & 166 [147-218] & 0.843 & 148 [115-207] & 153 [128-244] & 0.45 \\
\hline Mean E/e' ratio & $13.2[10.3-19.6]$ & $9.7[9.4-14.1]$ & $13.1[10.1-14.3]$ & 0.383 & $16.5[13.3-31.0]$ & $14.2[12.5-25.5]$ & 0.662 \\
\hline
\end{tabular}

Values are mean $\pm \mathrm{SD}$, median [interquartile range], or $n(\%)$

$A C E-I$ Angiotensin-converting enzyme inhibitor, $A l b$ albumin, $A R$ aortic regurgitation, $A R B$ angiotensin-receptor blocker, $A S$ aortic stenosis, $B M I$ body mass index, $B N P$ B-type natriuretic peptide, $D d$ diastolic dimension, $D s$ systolic dimension, $D T$ deceleration time, $E$ peak early mitral inflow velocity, $e$ ' peak early diastolic velocity at the mitral annulus, $E D V$ end-diastolic volume, $E F$ ejection fraction, $e G F R$ estimated glomerular filtration rate, $E S V$ endo-systolic volume, $H b$ hemoglobin, $H b A l c$ hemoglobin A1c, $H F p E F$ heart failure with preserved ejection fraction, $H F r E F$ heart failure with reduced ejection fraction, $h s-T n T$ high-sensitivity troponin T, $L A D$ left atrial dimension, $L V$ left ventricular, $M R$ mitral regurgitation, MRA mineralocorticoid receptor antagonist, NYHA New York Heart Association 
Table 2 Univariate Spearman's rank correlations between high-sensitivity troponin $\mathrm{T}$ and clinical indices in patients with heart failure with preserved ejection fraction

\begin{tabular}{lcc}
\hline Variable & Spearman's $r$ & $p$ value \\
\hline Age (years) & 0.093 & 0.446 \\
Sex & -0.202 & 0.109 \\
$\mathrm{Hb}(\mathrm{g} / \mathrm{dL})$ & -0.188 & 0.137 \\
$\mathrm{Alb}(\mathrm{g} / \mathrm{dL})$ & -0.053 & 0.678 \\
$\mathrm{eGFR}\left(\mathrm{mL} / \mathrm{min} / 1.73 \mathrm{~m}^{2}\right)$ & -0.141 & 0.267 \\
$\mathrm{BNP}(\mathrm{pg} / \mathrm{mL})$ & 0.182 & 0.175 \\
$\mathrm{LAD}(\mathrm{mm})$ & 0.176 & 0.164 \\
LVEDV Index $\left(\mathrm{mL} / \mathrm{m}^{2}\right)$ & -0.006 & 0.965 \\
LVESV Index $\left(\mathrm{mL} / \mathrm{m}^{2}\right)$ & 0.041 & 0.753 \\
Mean E/e' ratio & 0.240 & 0.568 \\
\hline
\end{tabular}

Alb Albumin, BNP B-type natriuretic peptide, $E$ peak early mitral inflow velocity, $e^{\prime}$ peak early diastolic velocity at the mitral annulus, $E D V$ end-diastolic volume, $E F$ ejection fraction, $e G F R$ estimated glomerular filtration rate, $E S V$ endo-systolic volume, $H b$ hemoglobin, $L A D$ left atrial dimension, $L V$ left ventricular

\section{The prognostic impact of hs-TnT}

During a median follow-up of 449 days [interquartile range: 260-780], 60/155 (39\%) patients experienced an adverse event (all-cause mortality, 31; non-fatal myocardial infarction, 2; non-fatal stroke, 2; HF hospitalization, 45). Adverse events occurred in 28 (44\%) HFpEF group patients (allcause mortality, 12; non-fatal myocardial infarction, 1 ; nonfatal stroke, 1; HF hospitalization, 23) and 32 (35\%) HFrEF group patients (all-cause mortality, 19; non-fatal myocardial infarction, 1; non-fatal stroke, 1; HF hospitalization, 22). There were 3 (4\%) patients in $\mathrm{HFpEF}$, and 7 (8\%) patients in HFrEF who had elevated hs-TnT over the upper reference limit of the troponin assay (i.e., hs-TnT $\geq 100 \mathrm{ng} / \mathrm{L}$ ).

In our hs-TnT ROC analysis, the area under the curve was greatest at an optimal cutoff point of $25.5 \mathrm{ng} / \mathrm{L}$ in the HFpEF cohort (Fig. 1). The area under the curve was greater in hsTnT than in BNP assays. High hs-TnT levels were related to an increased risk of adverse events in both HFpEF and HFrEF groups (Fig. 2). In Kaplan-Meier analysis, hs-TnT $\geq 25.5 \mathrm{ng} / \mathrm{L}$ predicted adverse events in the HFpEF group (Fig. 3). In multivariate Cox proportional hazards analysis, hs-TnT $\geq 25.5 \mathrm{ng} / \mathrm{L}$ predicted adverse events after adjustment for age, sex, eGFR, hemoglobin, albumin, and BNP in patients with HFpEF (Table 3).

\section{Discussion}

In this study, we identified a significant association between elevated hs-TnT at discharge and adverse events in patients hospitalized with decompensated HFpEF. This association

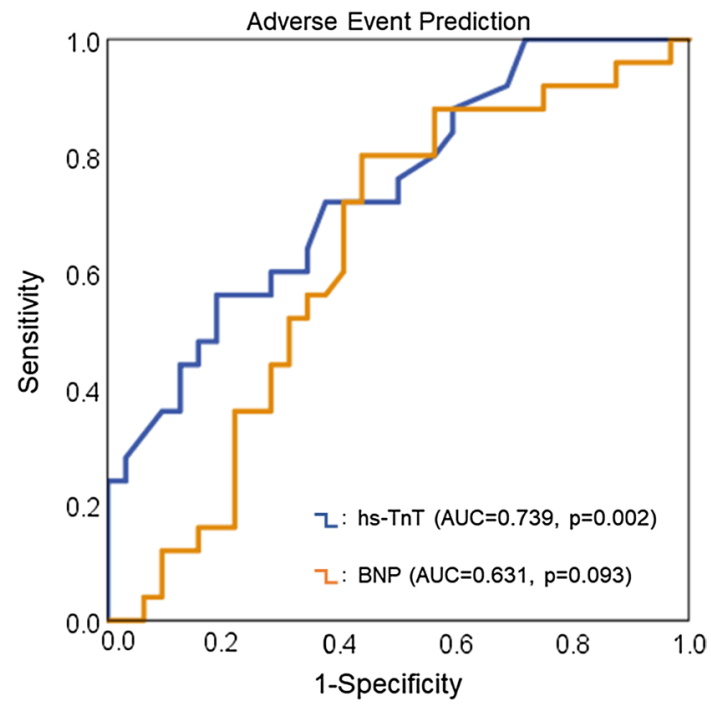

Fig. 1 Receiver operating characteristic curve for the prediction of adverse cardiac events in patients with heart failure with preserved ejection fraction-the greatest area under the high-sensitivity troponin $\mathrm{T}$ (hs-TnT) receiver operating characteristic (ROC) curve (AUC) - occurs at the optimal cutoff point of $25.5 \mathrm{ng} / \mathrm{L}$. Blue line, hs-TnT; orange line, B-type natriuretic peptide (BNP)

was independent of other well-established laboratory risk predictors, including BNP. A recent study reported the value of hs-TnT and high-sensitivity troponin I for predicting adverse events in stable HFpEF and HFrEF [12]. However, to our knowledge, no prior studies investigated the use of hs-TnT in Japanese elderly patients with decompensated HFpEF. In this study, we demonstrated that hs-TnT has prognostic

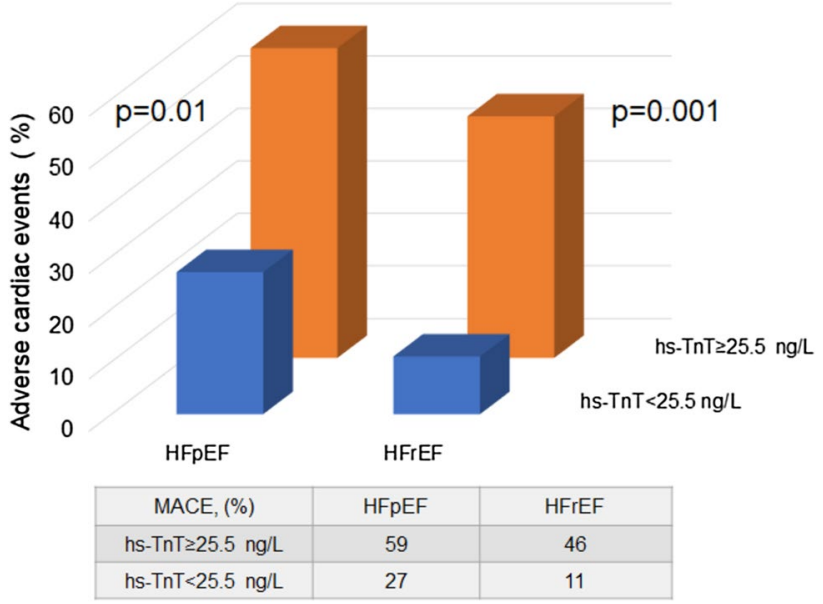

Fig. 2 Incidence of cardiac events according to high-sensitivity troponin $\mathrm{T}$ level-elevated high-sensitivity troponin $\mathrm{T}$ (hs$\mathrm{TnT} \geq 25.5 \mathrm{ng} / \mathrm{L}$ ) — was related to an increased risk of major adverse cardiac events (all-cause mortality, non-fatal myocardial infarction, non-fatal stroke, and HF hospitalizations) in groups with heart failure with preserved ejection fraction $(\mathrm{HFpEF})$ and heart failure with reduced ejection fraction (HFrEF) 


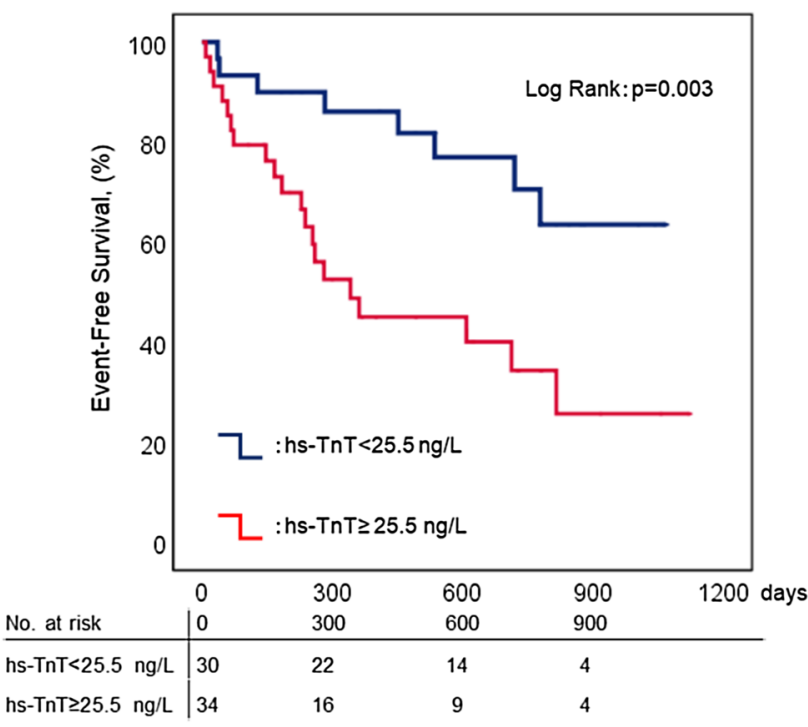

Fig. 3 Kaplan-Meier analysis of high-sensitivity troponin $\mathrm{T}$ in patients with heart failure with preserved ejection fraction-elevated high-sensitivity troponin $\mathrm{T}$ (hs-TnT $\geq 25.5 \mathrm{ng} / \mathrm{L}$ ) — predicted adverse cardiac events (red line). Blue line, hs-TnT $<25 \mathrm{ng} / \mathrm{L}$

Table 3 Multivariable Cox proportional hazards analysis in heart failure with preserved ejection fraction

\begin{tabular}{llc}
\hline Variables & HR $(95 \%$ CI $)$ & $p$ value \\
\hline hs-TnT adjusted for & & \\
Age, sex & $1.015(1.005-1.025)$ & 0.004 \\
Age, eGFR & $1.014(1.005-1.024)$ & 0.004 \\
Age, Hb & $1.015(1.005-1.025)$ & 0.003 \\
Age, Alb & $1.017(1.006-1.028)$ & 0.002 \\
Age, BNP & $1.016(1.005-1.027)$ & 0.005 \\
\hline
\end{tabular}

Alb Albumin, BNP B-type natriuretic peptide, $C I$ confidence interval, $e G F R$ estimated glomerular filtration rate, $H b$ hemoglobin, $H R$ hazard ratio, $h s-T n T$ high-sensitivity troponin $\mathrm{T}$

significance in this population. This finding has important clinical implications and suggests that hs-TnT is a useful riskstratification tool in cases of HFpEF. While several reports showed the prognostic significance of troponin $\mathrm{T}$ at admission $[9,10,12]$, our study indicates that the addition of hsTnT measurement at discharge could identify patients with HFpEF who require aggressive therapy and close outpatient follow-up. When talking about BNP, some studies report that the BNP value at discharge is a more accurate predictor of mortality in HF patients than that of admission or admissionto-discharge reduction [13]. Similarly, hs-TnT at discharge may be a better tool for prognostic prediction than troponin $\mathrm{T}$ at admission.

Myocyte cell death is the main pathology of troponin elevation in acute coronary syndrome. In HFrEF, the pathophysiological mechanism of myocardial injury and troponin elevation include subendocardial ischemia, neurohormonal activation, inflammatory cytokine release, altered calcium handling, oxidative stress, and increased wall stress [14]. Under these mechanisms, cardiac troponin shows significant relation with adverse cardiac events.

On the other hand, the fundamental pathophysiological mechanism of troponin elevation in HFpEF remains unclear. In HFpEF, ventricular diastolic dysfunction (impaired relaxation and increased diastolic stiffness) is typically present at rest or induced by stress (e.g., exercise, tachycardia, or hypertension) [15, 16]. Endothelial dysfunction, arterial stiffening, and increased ventricular systolic stiffness are also common [17]. Recently, systemic microvascular endothelial inflammation related to comorbid conditions has been proposed as another mechanism leading to myocardial inflammation and fibrosis and cardiomyocyte signaling pathway alterations. These alterations promote cell remodeling and dysfunction [18, 19], microvascular dysfunction and rarefaction in cardiac and skeletal muscle [20-23], and increases in oxidative stress [17]. From these backgrounds, troponin elevation in HFpEF might indicate the microvascular endothelial inflammation leading to myocardial death and subsequent fibrosis. However, this hypothesis is only speculative, and further studies are needed.

Our study had several limitations. First, we included a small number of patients taken from a single center. The number of patients is not enough to assess the prognostic value of hs-TnT, and the consecutive patients in this study represents a very selected cohort. Further research in a large cohort is necessary to verify our findings. Second, although elevated hs-TnT was independently associated with adverse events after adjusting for age and eGFR, HFpEF patients who had poor prognosis were older, and had impaired renal function. It is clear that these two indices are significantly associated with worse outcomes. To use hs-TnT as a riskstratification tool in Japanese elderly patients, association with cardiac death or HF re-admission should be investigated in larger studies. Third, only a single measure of hsTnT was available in each case, and serial hs-TnT levels were not evaluated. However, we measured hs-TnT at discharge when patients were in a stable phase of heart failure, and serial changes were expected to be rather small. Forth, patients who died in the hospital were not included in our study, and the most severe HF cases may have been excluded as a result. Finally, patients who underwent percutaneous coronary intervention during hospitalization were included in this study, which might have influenced in the hs-TnT at discharge. However, the median hs-TnT of these patients was 31 [24-45] ng/L, which had no difference compared to the total population (30 [19-50] $\mathrm{ng} / \mathrm{L}, p=0.557)$.

In conclusion, elevated hs-TnT was independently associated with adverse cardiac events in hospitalized patients 
with decompensated HFpEF. Our findings suggest that hsTnT may be a useful risk-stratification tool in this population. Further studies are needed to identify the multiple mechanisms leading to troponin $\mathrm{T}$ release in decompensated HFpEF.

Acknowledgements The authors acknowledge the secretarial assistance of Minako Aono.

\section{Compliance with ethical standards}

Conflict of interest There are no conflict of interest to declare.

Open Access This article is distributed under the terms of the Creative Commons Attribution 4.0 International License (http://creativeco mmons.org/licenses/by/4.0/), which permits unrestricted use, distribution, and reproduction in any medium, provided you give appropriate credit to the original author(s) and the source, provide a link to the Creative Commons license, and indicate if changes were made.

\section{References}

1. Owan TE, Hodge DO, Herges RM, Jacobsen SJ, Roger VL, Redfield MM (2006) Trends in prevalence and outcome of heart failure with preserved ejection fraction. N Engl J Med 355:251-259

2. Bhatia RS, Tu JV, Lee DS, Austin PC, Fang J, Haouzi A, Gong Y, Liu PP (2006) Outcome of heart failure with preserved ejection fraction in a population-based study. N Engl J Med 355:260-269

3. Sato Y, Kuwabara Y, Taniguchi R, Nishio Y, Miyamoto T, Fujiwara H, Takatsu Y (2008) Malignant link between chronic heart failure and acute cardiac decompensation in patients with persistently increased serum concentrations of cardiac troponin. Int $\mathbf{J}$ Cardiol 126:171-176

4. Ponikowski P, Voors AA, Anker SD, Bueno H, Cleland JGF, Coats AJS, Falk V, González-Juanatey JR, Harjola VP, Jankowska EA, Jessup M, Linde C, Nihoyannopoulos P, Parissis JT, Pieske B, Riley JP, Rosano GMC, Ruilope LM, Ruschitzka F, Rutten FH, van der Meer P, ESC Scientific Document Group (2016) 2016 ESC Guidelines for the diagnosis and treatment of acute chronic heart failure: The Task Force for the diagnosis and treatment of acute and chronic heart failure of the European Society of Cardiology (ESC) Developed with the special contribution of the Heart Failure Association (HFA) of the ESC. Eur Heart J 37:2129-2200

5. Yancy CW, Jessup M, Bozkurt B, Butler J, Casey DE Jr, Colvin MM, Drazner MH, Fillippatos GS, Fonarow GC, Givertz MM, Hollenberg SM, Lindenfeld J, Masoudi FA, McBride PE, Peterson PN, Stevenson LW, Westlake C (2017) 2017 ACC/AHA/HFSA focused update of the 2013 ACCF/AHA guidelines for the management of heart failure: a report of the American College of Cardiology/American Heart Association Task Force on Clinical Practice Guidelines and the Heart Failure Society of America. Circulation 136:e137-e161

6. Braga JR, Tu JV, Austin PC, Chong A, You JJ, Farkouh ME, Ross HJ, Lee DS (2013) Outcomes and care of patients with acute heart failure syndromes and cardiac troponin elevation. Circ Heart Fail 6:193-202

7. Pang PS, Teerlink JR, Voors AA, Ponikowski P, Greenberg BH, Fillippatos G, Felker GM, Davison BA, Cotter G, Kriger J, Prescott MF, Hua TA, Severin T, Metra M (2016) Use of highsensitivity troponin $\mathrm{T}$ to identify patients with acute heart failure at lower risk for adverse outcomes: an exploratory analysis from the RELAX-AHF Trial. JACC Heart Fail 4:591-599

8. Latini R, Masson S, Anand IS, Missov E, Carlson M, Vago T, Angelici L, Barlera S, Parrinello G, Maggioni AP, Tognoni G, Cohn JN, Investigators Val-HeFT (2007) Prognostic value of very low plasma concentrations of troponin $\mathrm{T}$ in patients with stable chronic heart failure. Circulation 116:1242-1249

9. Thawabi M, Hawatmeh A, Studyvin S, Habib H, Shamoon F, Cohen M (2017) Cardiac troponin and outcome in decompensated heart failure with preserved ejection fraction. Cardiovasc Diagn Ther 7:359-366

10. Pandey A, Golwala H, Sheng S, DeVore AD, Hernandez AF, Bhatt DL, Heidenreich PA, Yancy CW, de Lemos JA, Fonarow GC (2017) Factors associated with and prognostic implications of cardiac troponin elevation in decompensated heart failure with ejection fraction: findings from the American Heart Association get with the guidelines-heart failure program. JAMA Cardiol 2:136-145

11. Nagueh SF, Smiseth OA, Appleton CP, Byrd BF, Dokainish H, Edvardsen T, Flachskampf FA, Gillebert TC, Klein AL, Lancellotti P, Marino P, Oh JK, Popescu BA, Waggoner AD (2016) Recommendations for the evaluation of left ventricular diastolic function by echocardiography: an update from the American Society of Echocardiography and the European Association of Cardiovascular Imaging. J Am Soc Echocardiogr 29:277-314

12. Gohar A, Chong JPC, Liew OW, den Ruijter H, de Kleijn DPV, Sim D, Yeo DPS, Ong HY, Jaufeerally F, Leong GKT, Ling LH, Lam CSP, Richard AM (2017) The prognostic value of highly sensitive cardiac troponin assays for adverse events in men and women with stable heart failure and a preserved vs. reduced ejection fraction. Eur J Heart Fail 19:1638-1647

13. Omar HR, Guglin M (2016) Discharge BNP is a stronger predictor of 6-month mortality in acute heart failure compared with baseline BNP and admission-to-discharge percentage BNP reduction. Int $\mathrm{J}$ Cardiol 221:1116-1122

14. Kociol RD, Pang PS, Gheorghiade M, Fonarow GC, O'Connor CM, Felker GM (2010) Troponin elevation in heart failure prevalence, mechanisms, and clinical implications. J Am Coll Cardiol 56:1071-1078

15. Gladden JD, Linke WA, Redfield MM (2014) Heart failure with preserved ejection fraction. Pflugers Arch 466:1037-1053

16. Borlaug BA (2014) Mechanisms of exercise intolerance in heart failure with preserved ejection fraction. Circ J 78:20-32

17. Redfield MM (2016) Heart failure with preserved ejection fraction. N Engl J Med 375:1868-1877

18. Paulus WJ, Tschöpe C (2013) A novel paradigm for heart failure with preserved ejection fraction: comorbidities drive myocardial dysfunction and remodeling through coronary microvascular endothelial inflammation. J Am Coll Cardiol 62:263-271

19. Shah SJ, Kitzman DW, Borlaug BA, van Heerebeek L, Zile MR, Kass DA, Paulus WJ (2016) Phenotype-specific treatment of heart failure with preserved ejection fraction: a multiorgan roadmap. Circulation 134:73-90

20. Mohammed SF, Hussain S, Mirzoyev SA, Edwards WD, Maleszewski JJ, Redfield MM (2015) Coronary microvascular rarefaction and myocardial fibrosis in heart failure with preserved ejection fraction. Circulation 131:550-559

21. Mohammed SF, Majure DT, Redfield MM (2016) Zooming in on the microvasculature in heart failure with preserved ejection fraction. Circ Heart Fail 9:e003272

22. Dhakal BP, Malhotra R, Murphy RM, Pappagianopoulos PP, Baggish AL, Weiner RB, Houstis NE, Eisman AS, Hough SS, Lewis GD (2015) Mechanisms of exercise intolerance in heart failure with preserved ejection fraction: the role of abnormal peripheral oxygen extraction. Circ Heart Fail 8:286-294 
23. Haykowsky MJ, Tomczak CR, Scott JM, Paterson DI, Kitzman DW (2015) Determinants of exercise intolerance in patients with heart failure and reduced or preserved ejection fraction. J Appl Physiol 119:739-744

Publisher's Note Springer Nature remains neutral with regard to jurisdictional claims in published maps and institutional affiliations. 